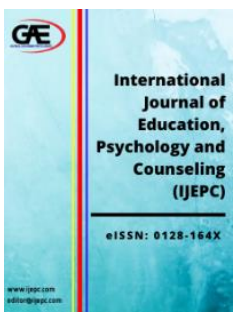

\author{
INTERNATIONAL JOURNAL OF \\ EDUCATION, PSYCHOLOGY \\ AND COUNSELLING \\ (IJEPC) \\ www.ijepc.com
}

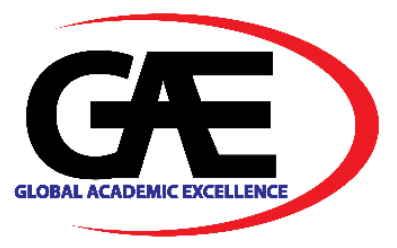

\title{
THE INFLUENCE OF IDIOMS ACQUISITION ON ENHANCING ENGLISH STUDENTS FLUENCY
}

\author{
Kamariah Yunus $^{1}$, Marvet Abed Ahmad Hmaidan ${ }^{2}$ \\ 1 Faculty of Language and Communication, Sultan Zainal Abidin University, Malaysia \\ Email: kamariah@unisza.edu.my \\ 2 Faculty of Language and Communication, Sultan Zainal Abidin University, Malaysia \\ Email: marvet_hmaidan@yahoo.com
}

\section{Article Info:}

\section{Article history:}

Received date: 21.04 .2021

Revised date: 30.03 .2021

Accepted date: 25.05.2021

Published date: 25.06.2021

\section{To cite this document:}

Yunus, K., \& Hmaidan, M. A. A. (2021). The Influence of Idioms Acquisition on Enhancing English Students Fluency. International Journal of Education, Psychology and Counseling, 6 (40), 124-133.

DOI: $10.35631 /$ IJEPC.640010.

This work is licensed under $\mathrm{CC}$ BY 4.0

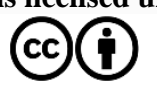

\begin{abstract}
:
Proficiency in figurative language is a challenging aspect of second language acquisition. An essential component of figurative fluency and proficiency is knowledge of idioms. Mastery of these formulaic sequences has been considered as an important indicator of communicative competence, enabling speakers to use the language both fluently and idiomatically. However, learning such essentially perplexing constructs poses a lot of challenges to EFL students, and thus they need to get immersed in language skills provided by teachers. The purpose of language acquisition is to achieve effective communication. Being communicatively competent helps language learners to avoid any kind of breakdown of communication, and therefore reaching fluency is the main goal of EFL learners. Thus, this quantitative study is an attempt to explore the influence of idioms acquisition on enhancing English students' fluency. The study has been carried out with twenty lecturers where a five-point Likert-scale questionnaire was employed to obtain data for the study. The collected data were analyzed statistically using SPSS software. The findings revealed that the participants have a positive attitude towards the impact of idioms acquisition on enhancing English students' fluency and acknowledged the importance of learning such expressions. The study concludes by a thorough discussion of the findings in relation to pedagogical implications in the field of second language teaching and learning.
\end{abstract}

Keywords:

Acquisition; EFL Learners; Figurative Language; Fluency; Idioms 


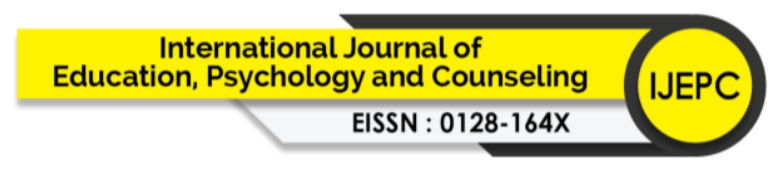

Volume 6 Issue 40 (June 2021) PP. 124-133

DOI 10.35631/IJEPC.640010

\section{Introduction}

As the English language is rich in idioms, learning them constitutes the soul of the language (Elkiliç, 2008). The main reason for the importance of idioms is that they are pervasive in everyday language, and thus acquisition of them is essential for successful communication and reaching native-like fluency. In the words of Johnson-Laird (1993), idioms are mysterious, pervasive, and poetic. They become the vehicle of thoughts, which is reborn in a speech in the form of living images; contributing to the creation of a figurative picture of the world and conveying native speakers' cultural codes (Savitsky, 2019). Such expressions provide the language with diversity and imagination (Cooper, 1999) and their acquisition embodies understanding a particular culture.

Idioms have been traditionally defined as multiword units whose figurative meanings cannot be derived from their individual words, and it is indeed their composite and colourful nature that has fascinated linguists and researchers for a long time. Liu (2008) defines an idiom as a multiword expression that is invariant or variance-restricted in structure and often non-or semiliteral in meaning. In her book, "In Other Words", Baker (2018) defines idioms as frozen patterns of language that allow only minor changes in their form and usually carrying a meaning that can't be predicted from their individual constituents.

While such expressions are pervasive in the native language, they are much less frequently used by L2 learners in their L2 (Güngör and Uysal, 2020). Even proficient L2 learners experience difficulties in understanding and using idioms (Ellis et al., 2008). This difficulty arises from the fact that L2 learners are less exposed to the L2 and particularly to L2 idioms (Wray, 2002) than native speakers do. It is not surprising, then, that English language learners usually struggle to speak fluently. Considering that native speakers use idioms naturally that they are generally unaware of their special nature, whereas idioms usually constitute a major stumbling block for non-native speakers. Native speakers can speak in special riddles, we call these riddles idioms unless we have the misfortune not to be a native speaker (Johnson-Laird, 1993).

Idioms are an important component of language and they contribute to fluency (Nation and Meara, 2020). Schmitt and Rodgers (2020) claim that formulaic language plays an important role in facilitating language; it is the key to fluency and inspires learners. Teaching and learning idioms have a lot of advantages for learners, such as enhancing receptive and productive competencies that can support L2 learners in different settings (Hinkel, 2017), also understanding the target language speakers' culture (Liontas, 2017). Thus, as figurative expressions, they help to enhance fluency and understanding which in turn increases students' self-confidence (Oxford, 1990). As a result, mastery of idioms is an indicator of second language fluency. The acquisition of these figurative formulaic sequences is a key element of linguistic competence (Boers et al., 2009; Cooper, 1999; Liu, 2008) as L2 fluency depends on accurately using figurative lexical items. It is reasonable to say that idioms can improve EFL learners' conversational skills because they show that one can understand and use the cultural meaning and context behind the idiom being using.

The important role of vocabulary in L2 learning has been well-established in L2 research (Astika, 2018). EFL learners often try to be fluent speakers of the language they are learning. In the words of Chambers (1997), fluency is about the efficiency of language use within the constraints of limited linguistic knowledge. For him, a speaker who can balance prefabricated 


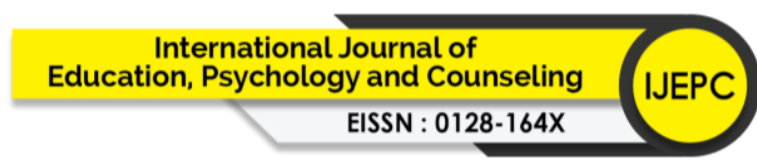

Volume 6 Issue 40 (June 2021) PP. 124-133

DOI 10.35631/IJEPC.640010

constructions with novel constructions gives the impression of a more fluent speaker. For Harmer (2007), the term speaking fluency is associated with the meaning of communication. Besides, Boers et al. (2006) confirms that language fluency has been interrelated with knowledge and use of multiword expressions. Thus, it could be said that, according to Elkiliç (2008), idioms are an important part of any language and an indicator of one's fluency in that language. In other words, idioms are used to assess the learners' language proficiency (AlHouti and Aldaihani, 2018) whereas the absence of idiomatic competence classifies the learner as a member of the foreigner camp (Bulut and Çelik-Yazici, 2004).

Figurative competence is an essential element of L2 fluency and thus in order to be proficient in a foreign language, L2 learners need to acquire a large repertoire of conventionalized expressions such as idioms. Therefore, raising learners' awareness and knowledge of lexical items boosts their language fluency and brings native-like production. It is believed that prefabricated chunks such as idioms help learners to enhance fluency, especially in spoken language as they are retrieved from the memory with less hesitation (Boers et al., 2006). It follows that lack of figurative competence is the main reason why foreign language students fail to achieve native-like fluency (Danesi, 1992).

\section{Literature Review}

Idiomatic language has gained a lot of attention for its relatively significant influence on EFL learners' fluency and their ability to communicate. A great deal of studies has highlighted the positive impact that idioms acquisition plays on enhancing English students fluency.

Qadr and Madhat (2020) conducted a study in which they attempted to explore the relationship between idiomatic knowledge and second language proficiency of English students in some Iraq universities. The researchers found that the relationship between idiomatic knowledge and language proficiency definitely exists. Likewise, Ali et al. (2019) investigated the importance of idiomatic expressions knowledge to promote English language fluency. The researchers found that knowledge of idiomatic expressions is important for students to promote language fluency.

Within the same effort, Rafieya (2018) explored the relationship between knowledge of formulaic sequences and language proficiency. The findings showed a strong positive relationship between language learners' knowledge of target language formulaic sequences and their level of language proficiency. In the same context, Mohammadi and Enayati (2018) examined the effects of learning lexical chunks (common idioms and collocations) on the speaking fluency of EFL Iranian learners. Their findings revealed that exposure to extensive lexical chunks had a positive impact on the speaking fluency development of learners, and thus learning lexical chunks had a major impact on the participants' speaking fluency.

Al-Houti and Aldaihani (2018) conducted a study to investigate EFL college students' attitudes towards idioms learning. One of the study goals was in revealing students' attitudes towards the importance of idioms learning. The findings revealed that students had positive attitudes towards English idioms learning, and they were aware of the importance of idioms because they reflect proficiency and incorporate cultural aspects. Furthermore, McGuire and LarsonHall (2017) investigated if explicitly teaching formulaic sequences to classroom ESL learners would improve the use of such language, which could result in improving L2 fluency. The researchers found that explicitly teaching formulaic sequences could lead to an increase in the 


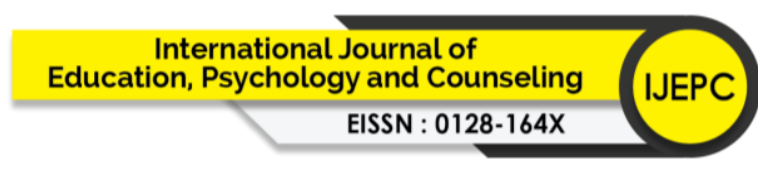

Volume 6 Issue 40 (June 2021) PP. 124-133

DOI 10.35631/IJEPC.640010

use of such phrases, and also increase the fluency of non-native speakers who speak English as a second language.

Speaking fluency has been widely investigated in EFL contexts. For example, Thomson (2017) investigated the effect of fluency-oriented classroom teaching on speaking fluency with special attention to multiword expressions. The findings showed a positive correlation between speech rate and the use of multiword expressions. In another study, Assassi and Benyelles (2016) noticed a great improvement in the EFL learners' formulaic language acquisition that helped them enhance fluency to their language accuracy and develop a solid communicative competence.

Liu (2017) unveiled the essentiality of idioms in second language acquisition. Liu argued that idiomatic expressions enable students to attain native-like performance. The author maintained that it reduces second language learner's hesitations; facilitates fluent language production and facilitate the fluency of native speakers.

Garnier and Schmitt (2016) contended that multiple meanings of idiomatic expressions may pose difficulties for L2 learners. For instance, back-up can mean "drive backwards", "take action to support someone's effort", or "establish as valid". Thyab (2016) investigated the importance of idiomatic expressions acquisition to English language learners. For him, lack of idioms knowledge is a lack of one's English language knowledge because idioms are very common in spoken and written English. The researcher concluded that learning idioms help non-native speakers become more fluent, and sound more native-like. Learning such expressions increases the lexicon of English language learners. Besides, idiomatic knowledge results in a better understanding of a particular culture of that language.

Adam (2015) explored the role of idiomatic expressions in enhancing communicative competence, and whether these expressions play an effective role in improving the students' performance in the English language. The study intended to focus on idiomatic expressions as important units of language. The main finding revolved around the importance of idiomatic expressions as important linguistic units for English students. This suggests that students' understanding of such expressions has an important role in enhancing their performance in language. Another result showed that effective teaching of idiomatic expressions will result in improving the students' communicative competence. Also, the study proposed that idiomatic expressions should be focused on within the syllabuses of universities, besides adopting effective approaches and strategies in teaching such linguistic elements.

The aforementioned studies in the field suggested idioms' positive impact on students' fluency and proficiency. The use of these expressions was found to be associated with native-like fluency. Many studies revealed that fluency could not be achieved without the use of formulaic language. It can then speculatively be said that mastery of a large number of idioms makes learners proficient speakers, and thus idioms acquisition helps to contribute to the strength of L2 fluency. The present study highlights a very important area of research to investigate the influence of idioms acquisition on enhancing English students fluency.

\section{Objectives Of The Study}

The objective of the present study is to explore the influence of idioms acquisition on enhancing the language fluency of English students. 


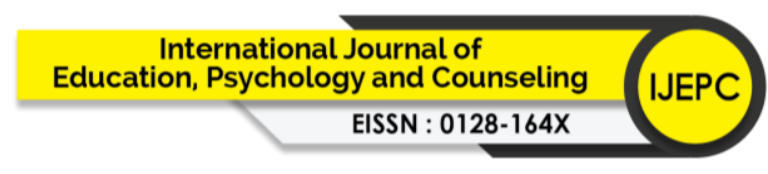

Volume 6 Issue 40 (June 2021) PP. 124-133

DOI 10.35631/IJEPC.640010

\section{Research Questions}

This study aims to answer the following question:

Does the acquisition of idioms influence the enhancement of English students' language fluency?

\section{Research Methodology}

The present study followed a quantitative approach to collect data wherein questionnaire items were formed after a thorough examination of the related literature. The questionnaire was designed and administered to a sample of twenty lecturers from different Jordanian universities to explore their opinions about the influence of idioms acquisition on enhancing language fluency of English students. The quantitative tool included 8 items with a five-point Likert scale (1: strongly disagree, 2: disagree, 3: neutral, 4: agree, and 5: strongly agree). A Cronbach's alpha was above .70, suggesting that the reliability of the instrument was satisfactory.

For the collection of the required data, several instruments including the English fluency test, grammar items, vocabulary items and reading comprehension items were used. To evaluate the influence of idioms acquisition on enhancing English students' fluency, one group pretest/post-test quasi-experimental design was conducted. The fluency of the participants was evaluated before and after the intervention sessions within which the participants were requested to implement peer-to-peer tutoring in enhancing English language fluency.

For the study purposes, Skehan's fluency measurement categorization (2005) was adopted with adaptations. The selected transcripts taken from the participants' oral performances were analysed focusing on measuring the rate of the existence of three major parameters during one selected minute from the audiotapes: 1) Speech repair includes repetition, correction and reformulation. 2) Speech breakdowns including unfilled pauses and filled pauses. 3) Speech rate: the measures of fluency conducted in this study are: Mean length of pauses where a pause is an unfilled silence of longer than 0.25 a second; Mean number of filled pauses, e.g., em and er. Repair measures: mean number of repetitions, self-correction and reformulation aspects per minute. Speech rate: number of words per minute.

The participants were selected using purposive sampling. The collected data were analyzed statistically using SPSS software where frequency table and descriptive statistics were employed to summarize the participants' responses for each item.

\section{Analysis and Discussion}

The present study aimed to explore English lecturers' opinions about the influence of idioms acquisition on enhancing English students fluency, which was directly measured with a fivepoint Likert scale questionnaire consisting of 8 statements. The composite scores ranged from 1 to 5, with higher scores indicating more positive attitudes towards the sub-scale. The obtained results are presented in Table 1 as shown below. 
Volume 6 Issue 40 (June 2021) PP. 124-133

DOI 10.35631/IJEPC.640010

\begin{tabular}{|c|c|c|c|c|c|c|c|c|}
\hline No. & Statement & $\begin{array}{l}\text { Strongly } \\
\text { Disagree }\end{array}$ & Disagree & Neutral & Agree & $\begin{array}{l}\text { Strongly } \\
\text { Agree }\end{array}$ & Mean & SD \\
\hline 1 & $\begin{array}{l}\text { Idioms are an } \\
\text { important part of the } \\
\text { English language. }\end{array}$ & $0.00 \%$ & $0.00 \%$ & $25.00 \%$ & $65.00 \%$ & $10.00 \%$ & 3.85 & 5.43 \\
\hline 2 & $\begin{array}{l}\text { Learning idioms is } \\
\text { essential for English } \\
\text { language students. }\end{array}$ & $0.00 \%$ & $0.00 \%$ & $15.00 \%$ & $75.00 \%$ & $10.00 \%$ & 3.95 & 6.28 \\
\hline 3 & $\begin{array}{l}\text { Knowledge of idioms } \\
\text { improves } \\
\text { students' English } \\
\text { skills. }\end{array}$ & $0.00 \%$ & $0.00 \%$ & $20.00 \%$ & $75.00 \%$ & $5.00 \%$ & 3.85 & 6.36 \\
\hline 4 & $\begin{array}{l}\text { It is important to } \\
\text { encourage English } \\
\text { students to learn } \\
\text { idioms for effective } \\
\text { communication. }\end{array}$ & $0.00 \%$ & $0.00 \%$ & $35.00 \%$ & $55.00 \%$ & $10.00 \%$ & 3.75 & 4.85 \\
\hline 5 & $\begin{array}{l}\text { Idioms are useful in } \\
\text { everyday } \\
\text { communication. }\end{array}$ & $0.00 \%$ & $0.00 \%$ & $25.00 \%$ & $70.00 \%$ & $5.00 \%$ & 3.8 & 5.96 \\
\hline 6 & $\begin{array}{l}\text { Idioms are important } \\
\text { because they are } \\
\text { common in everyday } \\
\text { language. }\end{array}$ & $0.00 \%$ & $0.00 \%$ & $25.00 \%$ & $60.00 \%$ & $15.00 \%$ & 3.9 & 4.95 \\
\hline 7 & $\begin{array}{l}\text { It is necessary to } \\
\text { incorporate English } \\
\text { idioms into the } \\
\text { curriculum. }\end{array}$ & $0.00 \%$ & $0.00 \%$ & $35.00 \%$ & $65.00 \%$ & $0.00 \%$ & 3.65 & 5.87 \\
\hline 8 & $\begin{array}{l}\text { Acquisition of idioms } \\
\text { can enhance English } \\
\text { students fluency. }\end{array}$ & $0.00 \%$ & $0.00 \%$ & $10.00 \%$ & $75.00 \%$ & $15.00 \%$ & 4.05 & 6.28 \\
\hline
\end{tabular}

\section{Table 1: The Frequency Distribution for the Respondent's Responses}

Statement One: Idioms Are An Important Part Of The English Language.

The table shows that $75 \%$ of the participants strongly agreed or agreed that idioms are an important part of the English language. The high number of idioms in the English language makes them an important aspect of vocabulary. This indicates that these expressions are an important and undeniable part of English as a second language, and as such can hardly be avoided.

\section{Statement Two: Learning Idioms Is Essential For English Language Students.}

The findings showed that the participants had a positive attitude towards the importance of learning idioms with a percentage of $85 \%$ (strongly agreed or agreed). This indicates that learning idioms are a very important part of the language learning process. Learning idioms increases students' knowledge and improves their communicative skill, which helps them be better speakers. So, if students want to speak English fluently, it is necessary to learn and use idioms to improve their communicative skills. 


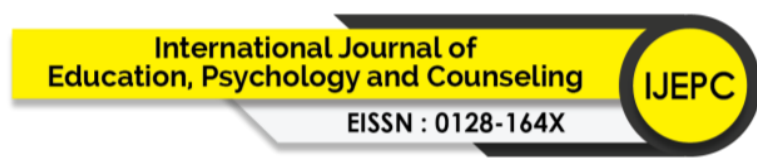

Volume 6 Issue 40 (June 2021) PP. 124-133

DOI 10.35631/IJEPC.640010

Statement Three: Knowledge Of Idioms Improves English Students' Language Skills.

From the table, it is clear that the majority of the participants agreed or strongly agreed with a percentage of $80 \%$ that knowledge of idioms is important to improve the students' language skills. It is reasonable to say that idioms can improve receptive and productive competencies that can support students in different settings. In this way, the students will be able to communicate better and will become more fluent in the English language.

\section{Statement Four: It Is Important To Encourage English Students To Learn Idioms For Effective Communication.}

Learning of idioms has a lot of advantages for students such as boosting communicative competence and achieving native-like language fluency. It seemed that the participants acknowledged the importance of encouraging English students to learn idioms. Thus, $65 \%$ of the participants strongly agreed or agreed on the importance of encouraging English students to learn idioms for effective communication.

\section{Statement Five: Idioms Are Useful In Everyday Communication.}

As the table reveals, the majority of the participants responded with agree or strongly agree to the statement with a percentage of $75 \%$. This result indicates a general awareness of the importance and benefit of idioms in everyday communication. These expressions play an important role in facilitating language and understanding others since a lot of daily speech is based on idioms.

Statement Six: Idioms Are Important Because They Are Common In Everyday Language. From the obtained results, $75 \%$ of the participants strongly agreed or agreed on the importance of idioms as they are an essential component of daily language usage. This reflects the importance of idioms in everyday situations as they are frequently encountered in spoken and written discourse.

\section{Statement Seven: It Is Necessary To Incorporate English Idioms In The Curriculum.}

From the table, it is clear that $65 \%$ of the participants agreed that idioms should be incorporated into the English language curriculum to enrich the students' idioms knowledge. This insured that students should be exposed to idiomatic language inside classrooms to learn and practice such expressions. So, including idioms in the syllabus is a very useful strategy to help the students enhance their communicative skills.

\section{Statement Eight: Acquisition Of Idioms Can Enhance English Students Fluency.}

The statistical analysis revealed that a great percentage (90\%) of the participants strongly agreed or agreed that there is a significant relationship between idioms acquisition and English students fluency. This indicates that the participants have a positive attitude towards the impact of idioms acquisition on enhancing English students fluency. One can say that acquisition of idioms can help students go deeper into the English language and culture.

In a nutshell, it can be concluded that the acquisition of idioms can enhance English students fluency. Acquisition of such figurative expressions has become very important in English that it can allow students to speak or write fluently as it supports the vocabulary storage of the students. The findings are in line with those of Qadr and Madhat (2020), Ali et al. (2019), Rafieya (2018), Mohammadi and Enayati (2018), Al-Houti and Aldaihani (2018), McGuire and Larson-Hall (2017), Thomson (2017), Assassi and Benyelles (2016), Thyab (2016), and 


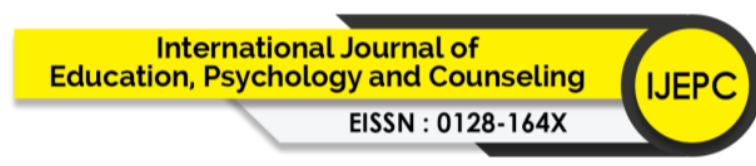

Volume 6 Issue 40 (June 2021) PP. 124-133

DOI 10.35631/IJEPC.640010

Adam (2015) in that acquisition of idioms can help students enhance fluency to their language accuracy and develop a solid communicative competence. In other words, exposure to such figurative expressions has a positive impact on the students' fluency, and thus lecturers acknowledged the importance of learning such expressions.

\section{Conclusion}

Idioms are so prevalent in the English language that, in order to enhance students' fluency, students need to get familiar with the most common idioms for situations they aim to use the language in. Acquisition of idioms can be considered as an essential part of language learning since idiomatic language helps learners to speak and write fluently. Therefore, these figurative expressions should be taught in EFL contexts in order to enhance the fluency and naturalness of students' language. The study concluded that idioms are an important part of English language acquisition and an indicator of second language fluency. Mastery of these formulaic sequences has been considered as an important indicator of communicative competence, enabling speakers to use the language both fluently and idiomatically.

The ability to learn and use idioms is considered to be the largest barrier to fluency in second language acquisition, and one of the language aspects that students struggle with. That is why learning the idiomatic language in classrooms plays a significant role in foreign language acquisition. Pedagogically, this study can raise students and teachers' awareness about the importance of idioms acquisition and its significant role in enhancing students' fluency and naturalness in speaking English.

\section{References}

Adam, A. (2015). The Role of Idiomatic Expressions in Improving Communicative Competence of EFL Learners. Master Thesis, University of Gezira, Sudan.

Al-Houti, S. and Aldaihani, S. (2018). Letting the Cat Out of the Bag: EFL College Students' Attitudes towards Learning English Idioms. International Journal of Higher Education, 7(1), 140-150.

Ali, A., Hadidi, M., and Elumarabi, M. (2019). The Influence of the Idiomatic Expressions on Enhancing EFL Language Fluency. International Journal of English Language, Literature and Translation Studies, 6(2), 88-96.

Assassi, T. and Benyelles, R. (2016). Formulaic Language for Improving Communicative Competence. Arab World English Journal, 7(2), 163-176.

Astika, G. (2018). Lemmatizing Textbook Corpus for Learner Dictionary of Basic Vocabulary. Indonesian Journal of Applied Linguistics, 7(3), 630-637.

Baker, M. (2018). In Other Words: A Course Book on Translation. Routledge.

Boers, F., Eyckmans, J., Kappel, J., Stengers, H., and Demecheleer, M. (2006). Formulaic Sequences and Perceived Oral Proficiency: Putting a Lexical Approach to the Test. Language Teaching Research, 10(3), 245-261.

Boers, F., Piquer Píriz, A., Stengers, H., and Eyckmans, J. (2009). Does Pictorial Elucidation Foster Recollection of Idioms? Language Teaching Research, 13, 367-382.

Bulut, T. and Çelik-Yazici, Y. (2004). Idiom Processing in L2: Through Rose-colored Glassed. The Reading Matrix, 4, 105-116.

Chambers, F. (1997). What Do We Mean By Fluency? System, 25(4), 535-544.

Cooper, T. (1999). Processing of Idioms in L2 Learners of English. TESOL Quarterly, 33(4), 233- 262. 


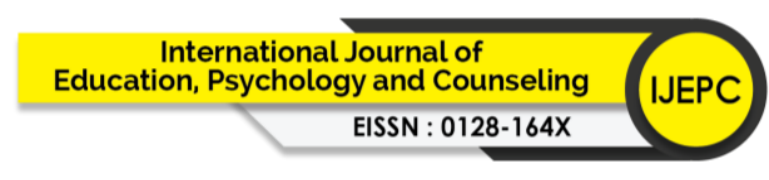

Volume 6 Issue 40 (June 2021) PP. 124-133

DOI 10.35631/IJEPC.640010

Danesi, M. (1992). Metaphorical Competence in Second Language Acquisition and Second Language Teaching: The Neglected Dimension. In J. E. Alatis (Ed.), Georgetown University Round Table on Languages and Linguistics (pp. 489-500). Washington, DC: Georgetown University Press.

Elkiliç, G. (2008). Turkish Students' Understanding of Transparent and Opaque Idioms in English in Reading As Well As In Speaking. Journal of Language and Linguistic Studies, 4(2), 27-41.

Ellis, N., Simpson-Vlach, R., and Maynard, C. (2008). Formulaic Language in Native and Second Language Speakers: Psycholinguistics, Corpus Linguistics, and TESOL. TESOL Q., 42(3), 375-396.

Garnier, M., \& Schmitt, N. (2016). Picking up polysemous phrasal verbs: How many do learners know and what facilitates this knowledge. System, 59, 29e44. https://doi.org/10.1016/j.system.2016.04.004

Güngör, F. and Uysal, H. (2020). Lexical Bundle Use and Cross linguistic Influence in Academic Texts. Lingua 242.

Harmer, J. (2007). The Practice of English Language Teaching (4 ${ }^{\text {th }}$ Edition). Edinburgh, UK: Pearson.

Hinkel, E. (2017). Teaching Idiomatic Expressions and Phrases: Insights and Techniques. Iranian Journal of Language Teaching Research, 5(3), 45-59.

Johnson-Laird, P. (1993). Foreword. In C. Cacciari and P. Tabossi (Eds.), Idioms: Processing, Structure, and Interpretation (pp. VII-X). Hillsdale, NJ: Lawrence Erlbaum Associates.

Liontas, J. (2017). Why teach Idioms? A Challenge to the Profession. Iranian Journal of Language Teaching Research, 5(3), 5-25.

Liu, D. (2008). Idioms: Description, Comprehension, Acquisition, and Pedagogy. New York: Routledge.

Liu, D. (2017). Idioms: Description, comprehension, acquisition, and pedagogy. New York: Routledge.

McGuire, M. and Larson-Hall, J. (2017). Teaching Formulaic Sequences in the Classroom: Effects on Spoken Fluency. TESL Canada Journal, 34(3), 1-25.

Mohammadi, M. and Enayati, B. (2018). The Effects of Lexical Chunks Teaching on EFL Intermediate Learners' Speaking Fluency. International Journal of Instruction, 11(3), 179-192.

Nation, P. and Meara, P. (2020). Vocabulary. In Schmitt and Rodgers, An Introduction to Applied Linguistics. NY: Routledge.

Oxford, R. (1990). Language Learning Strategies: What Every Teacher Should Know. Boston: Heinle and Heinle Publishers.

Qadr, H. and Madhat, I. (2020). The Relationship between Idiomatic Knowledge and Second language Proficiency/Kurdistan Universities Undergraduates as an Example. International Journal of Linguistics, Literature and Translation, 3(8), 149-160.

Rafieya, V. (2018). Knowledge of Formulaic Sequences as a Predictor of Language Proficiency. International Journal of Applied Linguistics and English Literature, 7(2), 64-69.

Savitsky V. (2019). Cultural Codes: Essence, Structure and Functioning in the Process of Communication. Professional Discourse and Communication, 1(4), 68-77.

Schmitt, N. and Rodgers, M. (2020). An Introduction to Applied Linguistics. NY: Routledge. Thomson, H. (2017). Building Speaking Fluency with Multiword Expressions. TESL Canada Journal, 34(3), 26-53. 
Volume 6 Issue 40 (June 2021) PP. 124-133 DOI 10.35631/IJEPC.640010

Thyab, R. (2016). The Necessity of idiomatic expressions to English Language learners. International Journal of English and Literature, 7(7), 106-111.

Wray, A. (2002). Formulaic Language and the Lexicon. Cambridge University Press. 